\title{
Elements and (first) principles in chemistry
}

\author{
Robin Findlay Hendry ${ }^{1}$
}

Received: 15 November 2017 / Accepted: 1 July 2019 / Published online: 24 July 2019

(c) The Author(s) 2019

\begin{abstract}
The first principle of chemical composition is that elements are actually present in their compounds. It is a golden thread running through the history of compositional thinking in chemistry since before the chemical revolution. Opposed to this principle, which I call Actually Present Elements (APE), is the idea that elements are merely potentially present in their compounds: although not actually present, it is possible to recover them. In this paper I follow that golden thread, and then discuss the status of APE itself: is it true? What arguments were there for it, and when? I argue that APE is a metaphysical principle, albeit at a lower level of generality and abstraction than the term 'metaphysical' usually suggests. I critically examine a range of different views on how metaphysical principles might be involved in research programmes in empirical science, and conclude by endorsing Elie Zahar's view that metaphysical principles such as APE are to be found at the very heart of science. Moreover, they can be recipients of empirical support just like other parts of scientific theory.
\end{abstract}

Keywords Chemistry $\cdot$ Metaphysics $\cdot$ History of science

\section{Introduction}

For very good reasons, it is quite unfashionable for historians and philosophers of science to attempt to identify, in sweepingly general terms, grand 'research programmes' in science, that stretch across centuries. The historiographical danger of such accounts is that they tend to abstract away from, or even ignore entirely, the particular and quite distinct problem situations that faced the various historical scientists who worked at different stages of such programmes. Nevertheless, here is what I take to be an illuminating sketch of the history of chemistry: from Lavoisier onwards, chemists were engaged in a compositional research programme whose central task was to decompose non-elemental substances and identify their component elements.

Robin Findlay Hendry

r.f.hendry@durham.ac.uk

1 Department of Philosophy, Durham University, 50 Old Elvet, Durham DH1 3HN, UK 
Lavoisier assumed, but did not feel the need to argue for, a principle that I will call APE: the Actual Presence of Elements in their compounds. In case APE should seem trivial, it can be contrasted with a broadly Aristotelian view of chemical composition, according to which elements are merely potentially present in their compounds. APE provided a clear rationale for the new nomenclature Lavoisier and his collaborators proposed for chemistry, which (they hoped) would sweep away the uninformative 'trivial names' that (they felt) were a hindrance to chemical thinking. In the nineteenth century, Dalton introduced a new form of atomism, which provided a metaphysical explanation of APE: for each element there is a distinct kind of atom, and elements are present in their compounds because atoms survive chemical change, and so are actually present in their compounds. This was an innovation: before Dalton there were no direct logical relationships between atomist assumptions and compositional theory. Later in the nineteenth century, Mendeleev's periodic table was a table of elements to which APE was presumed to apply. Moving into the twentieth century, the increasingly close interaction between chemistry and physics vindicated APE, but importantly modified Dalton's metaphysical explanation for it. Dalton and Mendeleev both assumed that elements are individuated by their atomic weights. Following the discovery of isotopy, twentieth-century chemists and physicists came to see chemical elements as individuated instead by their atomic number (or better, by their nuclear charge). Twentieth-century scientists therefore retained Mendeleev's periodic table, but changed the quantity that defined each place in it.

It should be no surprise that chemists have made substantive metaphysical assumptions about chemical substances. Historians and philosophers long ago abandoned the view that science came into being by eliminating metaphysics. APE is an interesting case in point: although I argue that it is a 'golden thread' running through compositional theory since Lavoisier, it was never explicitly discussed, let alone argued for. Yet without APE it is hard to see how chemistry could have developed in the familiar way that it did from the end of the eighteenth century. APE grounds Lavoisier's introduction of gravimetric methods, which were such an important innovation in chemistry. It also grounds the compositional research programme: use laboratory investigation to identify which substances are composed of which others, which will furnish a growing list of substances that cannot be decomposed, but which can themselves be sought as components of compounds. ${ }^{1}$

In what follows I will begin by tracing APE through the history of chemistry up to the discovery of isotopy in the twentieth century. I will then move on to a discussion of the status of APE. Does modern chemistry vindicate this assumption? What was its epistemic status for the historical scientists who presumed its truth, but did not argue for it? I will argue that APE is a central, though tacit metaphysical assumption. If it is known today, it must be known a posteriori. I conclude by considering the role of metaphysical assumptions in scientific research programmes.

\footnotetext{
1 It is worthwhile emphasising that the compositional research programme is identified not only by APE, but also by the particular list of elements with which chemists worked from Lavoisier onwards. APE may have been a necessary part of that research programme, but was not itself sufficient.
} 


\section{APE in the history of the elements}

In this section I will begin by examining how elements were conceived before Lavoisier, and then go on to show that APE is a common commitment in the compositional thinking of Lavoisier, Dalton and Mendeleev. Now Lavoisier's work occasioned the disappearance of phlogiston from chemical thinking, an event that has been called the 'Chemical Revolution.' I will focus on APE, and will therefore not explore the detailed changes that took place in compositional theory during this time. Nor will I address the question of whether the disappearance of phlogiston theory was necessitated by evidence that was available at the time, or whether in some more general sense it was a Good Thing for the development of science (for differing views on which see Chang 2012; Blumenthal and Ladyman 2017, 2018).

\subsection{Early modern chemistry}

Conceptions of the elements (or principles) found in chemical texts of the seventeenth century bear no clear commitment to APE (Siegfried 2002, Chapter 1; Klein and Lefèvre 2007, Chapter 2). From the point of view of the explanatory role they assign to elements (or principles), they are often closer to Aristotle's view of combination (on which see below), though they are much less clear and systematically developed. The elements are few in number (whether 3, 4 or 5) and are often identified a priori. The resulting compositional theories have only a distant relationship to the understanding of particular kinds of chemical change studied in the laboratory. Elements need not be viewed as material parts of laboratory substances, but may instead contribute to the character of a composite substance by offering their characteristic properties: the properties of a composite substance are often assumed to be a blend of those of the elements of which it is composed, as in a broadly Aristotelian account. Some philosophers of this period hoped that this kind of speculation about the elements could be swept away by healthy doses of empiricism and mechanical philosophy, and Robert Boyle certainly tried to administer both. In The Sceptical Chymist he seems clearly to conceive of composition as material, and sets out what one might call an analytical conception of the elements ${ }^{2}$ :

And, to prevent mistakes, I must advertize you, that I now mean by Elements, as those Chymists who speak plainest do by their Principles, certain primitive and Simple or perfectly unmingled bodies; which not being made of any other bodies, or of one another, are the Ingredients of which all those call'd perfectly mixt Bodies are immediately compounded, and into which they are ultimately resolved. (1661, p. 350)

Boyle's view of the elements seems, however, to have been merely sceptical: he certainly rejected a priori speculation, but provided no positive framework for a detailed theory of the composition of substances (Siegfried 2002, Chapter 2). Boyle was sympathetic to atomism, which could clearly allow elements to be material components

\footnotetext{
2 I borrow the term from Cassebaum and Kauffman (1976), who apply it to chemical thinking in the eighteenth century.
} 
of substances, but his version of atomism gave no account of how many different kinds of atoms there are, nor any specific idea of how they, or combinations of them, might be related to the identity or behavior of particular laboratory substances. As Ursula Klein puts it (1994, p. 170), Boyle's atoms are not substance-specific components. They are unsuited to be the theoretical basis for compositional theory (Chalmers 2009, Chapter 8).

The eighteenth century brought a number of important changes in chemical theory and practice. Firstly there was a closer integration between compositional theory and expanding laboratory knowledge (Siegfried 2002, Chapter 4). Secondly, the atmosphere came to be regarded as an active agent of chemical change (Siegfried 2002, Chapter 6). Most importantly, however, Ursula Klein has argued that during this period there emerged a conception of chemical substances as composed of stable substancespecific material components (Klein 1994; Klein and Lefèvre 2007, Chapter 2). Klein attributes the change to the widespread use of affinity tables. The first of these is Etienne-François Geoffroy’s ‘Table des différents rapports' (Geoffroy 1718). Geoffroy's table set out the orders of affinity between various substances: how one substance $\mathrm{X}$ can displace another $\mathrm{Y}$ from a compound $\mathrm{YZ}$ if it has a higher degree of affinity for the other component $\mathrm{Z}$. The reactions were assumed to be reversible, with $\mathrm{X}, \mathrm{Y}$ and Z treated as 'building blocks' (Klein 1994, pp. 168-170) that persist as substancespecific material parts of substances throughout the changes he describes. To that extent they are 'relatively stable entities' (1994, p. 170), in that their identity is conserved through specific kinds of chemical change. Many such affinity tables were published in the eighteenth century, embodying the same general assumptions about composition (Klein and Lefèvre 2007, Chapters 8 and 9), assumptions which came to change the way chemists thought about hypothetical elements or principles such as phlogiston (see Klein and Lefèvre 2007, pp. 150-151). As a result, by the middle of the eighteenth century most chemists 'regarded the ultimate principles as a kind of physical component of mixts' (Klein and Lefèvre 2007, p. 114).

Klein's account is both plausible and very interesting, because it links a change in compositional concepts to the widespread use of a tool for reasoning during the relevant period. However, viewed as the historical explanation for the conception of element that Lavoisier took for granted, there are two questions that arise: these concern the relevance of the concept of chemical substance that emerges from Geoffroy's table, and its transmission through to Lavoisier. On the question of relevance, Geoffroy's affinity tables concern 'building blocks,' which Klein makes clear are not 'ultimate principles'. How do the assumptions that govern the building blocks in Geoffroy's table get transferred to elements? On the question of transmission, one might expect that if there is a close conceptual connection between Geoffroy's tables and elements, then the former might be mentioned wherever the latter are discussed. Surprisingly, for Klein's account, this is not the case. Even though Geoffroy's affinity tables are well known, mention of them is typically absent from discussions of the elements. ${ }^{3}$ As an illustration of these points, consider the third edition of Pierre-Joseph Macquer's Elements of the Theory and Practice of Chymistry (Macquer 1768). From a conceptual point of view, Macquer's discussion 'Of the Principles of Bodies' (1768, Chapter 1),

\footnotetext{
3 I am most grateful to an anonymous referee for bringing this to my attention.
} 
follows the traditional pattern described at the beginning of this section. It makes no mention of Geoffroy. Affinities are the subject of Macquer's Chapter 2, including the reversible kinds of change that Klein associates with Geoffroy (see in particular 1768, p. 13), but once again Geoffroy himself is not mentioned. Much later, when affinity tables are discussed, 'the late Mr. Geoffroy' does get a mention (1768, p. 159). The discussion of affinity tables has no particular relevance for elements, however, because many of the relationships of relative affinity which are discussed in that chapter hold between metals, which good phlogistonists (including Macquer himself) regarded as compound substances. If Geoffroy is the first cause of the assumptions underlying APE, how do Geoffroy's assumptions get transferred to elements, and then transmitted to Lavoisier, if not via such influential chemical authors as Macquer?

\subsection{Lavoisier}

Lavoisier made a crucial contribution to launching the compositional research programme in chemistry. He can be credited with identifying a number of key substances - oxygen, hydrogen and nitrogen — which are components of a very wide range of other substances. He can also be credited with identifying oxygen as the key agent of combustion and calcination. Furthermore in the 1780s, Lavoisier and his collaborators introduced a system of binomial nomenclature that remains in use in modern chemistry. This nomenclature was based on a project of identifying a list of the elements from which compound substances are composed. It was literally 'based on' such a project because the system took the names of the elements as the linguistic elements from which the binomial names of compound substances were to be formed. Thus, for Lavoisier, many simple substances, when heated in the air, form 'oxyds.' The compositional nomenclature formed the name of the compound from the names of its constituent elements.

Identifying the conception of the elements that underpinned all these contributions is more complex, however. In the preface to Lavoisier's Traité Elementaire de Chimie (Lavoisier 1790), he presented an analytical conception of what it is to be an element that is rather close to Boyle's. ${ }^{4}$ To be an element is to be the last point of chemical analysis:

[I]f we apply the term elements, or principles of bodies, to express our idea of the last point which analysis is capable of reaching, we must admit, as elements, all the substances into which we are capable, by any means, to reduce bodies by decomposition. Not that we are entitled to affirm, that these substances we consider as simple may not be compounded of two, or even of a greater number of principles; but, since these principles cannot be separated, or rather since we have not hitherto discovered the means of separating them, they act with regard to us as simple substances, and we ought never to suppose them compounded until experiment and observation has proved them to be so. (1790, p. 24)

\footnotetext{
${ }^{4}$ Since the analytical conception was explicitly presented by Boyle, and was an element of compositional thinking during the eighteenth century (Cassebaum and Kauffman 1976), it cannot be regarded as the conceptual spark for the chemical revolution (if indeed there was one).
} 
The analytical criterion implies that no substance should be regarded as a compound unless it can be decomposed. However, for Lavoisier the analytical conception of the elements was defeasible: he was willing to suspend it when (he thought) compositional theory demanded it. For instance, he says of the acid of sea-salt (hydrochloric acid, $\mathrm{HCl})$ :

Although we have not yet been able, either to compose or to decompound this acid of sea-salt, we cannot have the smallest doubt that it, like all other acids, is composed by the union of oxygen with an acidifiable base. We have therefore called this unknown substance the muriatic base, or muriatic radical. (1790, p. 72)

Sure enough, it is the 'muriatic radical' that appears in Lavoisier's table of simple substances (1790, p. 175), rather than the as-yet undecompounded acid of sea-salt. Why did he not have the 'smallest doubt' about its composition? In Chapter V of the Traité, Lavoisier had shown how sulphur, phosphorus and carbon all combine with oxygen from the air to form compounds which, when dissolved in water, display characteristically acidic behaviour (the above quote about the acid of sea-salt appears in Chapter VI). He infers from this a general claim about the composition of acids, that 'oxygen is an element common to them all, which constitutes their acidity; and that they differ from each other, according to the nature of the oxygenated or acidified substance' (1790, p. 65). This use of what might be called 'chemical analogy' to reach conclusions about the composition of substances is not an isolated case. On similar grounds he regarded gases as compounds, with caloric their common component (Lavoisier 1790, Chapter I; see also Hendry 2005); he also declined to list potash and soda on his table of simple substances because they are 'evidently compound substances, though we are ignorant as yet what are the elements they are composed of' (1790, p. 178).

The analytical conception did have one clear advantage as a working criterion: it ruled out the a priori schemes for the number or nature of the elements that had been common in earlier chemical theories, introducing a qualified empirical constraint into theories of chemical composition. The constraint is limited because it is a matter of compositional theory whether or not a particular chemical change involves the decomposition of one of the reagents. Gravimetric methods cannot always settle such matters: Lavoisier admitted imponderable (weightless) bodies, whose presence would have to be traced in other ways, into his table of simple substances (see Hendry 2010, Sect. 2). Hence the analytical criterion is at best a guide that can be applied only within a framework of compositional hypotheses that must answer to overall explanatory concerns.

The analytical conception is insufficient to motivate Lavoisier's own assumptions about the elements, which include APE. Aristotle's account of combination (see below) supports an analytical conception of the elements, but denies APE (Needham 2009). Nevertheless, Lavoisier is clearly committed to APE. Firstly, the binomial nomenclature makes sense only if APE is true. Secondly, in the Traité, element names are assumed to apply across different states of chemical combination, again presupposing APE: 
The metals, except gold, and sometimes silver, are rarely found in the mineral kingdom in their metallic state, being usually less or more saturated with oxygen, or combined with sulphur, arsenic, sulphuric acid, muriatic acid, carbonic acid, or phosphoric acid (1790, p. 159).

Thirdly, he described processes of chemical change in ways that presuppose the truth of APE. Consider, for instance, the following account of the combustion of metals, from the Preface to the Traité:

Metallic substances which have been exposed to the joint action of air and fire, lose their metallic lustre, increase in weight, and assume an earthy appearance. In this state, like the acids, they are compounded of a principle which is common to all, and one which is peculiar to each. In the same way, therefore, we have thought proper to class them under a generic name, derived from the common principle; for which purpose, we adopted the term oxyd; and we distinguish them from each other by the particular name of the metal to which each belongs. (Lavoisier 1790, p. 28)

Lastly, Lavoisier regarded the presence of an element in its compounds as central to understanding their chemical and physical behaviour (see Hendry 2010, Sect. 2). He also assumes that the weight of an element is conserved across chemical change, so that an element must be lighter than its compounds, a principle that was central to his criticism of phlogistonist theories of combustion. This makes perfect sense if elements are material components, but is unmotivated by the analytical criterion.

\subsection{Dalton}

Early in the nineteenth century, John Dalton introduced a strikingly new version of the atomic theory, which Rocke (1984) has called 'chemical atomism', to distinguish it from earlier forms of atomism, which offered no clear explanations of the chemical behaviour of substances. Dalton's new theory was clearly relevant to compositional theory: to each of Lavoisier's elements there corresponds a particular kind of atom. To borrow Klein's phrase, Dalton's atoms were substance-specific, unlike Boyle's. They survive chemical change, underwriting the tacit assumption of APE. Atoms of the same element are alike in their weight. On the assumption that atoms combine with the atoms of other elements in fixed ratios, Dalton's theory offered the sketch of an explanation of why, when elements combine, they do so with fixed proportions between their weights, and the fact that the same two elements may combine in different proportions to form distinct compounds (although see Needham 2004). Though Dalton's theory divided chemists, there is no doubt that chemical atomism offered a highly influential conception of composition.

The central empirical problem for the theory concerned how to estimate atomic weights. Although such tiny quantities could not be measured absolutely, they could be measured relative to a reference atom (the natural choice being hydrogen as 1), but how to set the ratio between the weights of different atoms? Dalton assumed that, if only one compound of two elements is known, it should be assumed that they combine in equal proportions. Water, for instance, was rendered as HO in the 
Berzelian formulae that chemists adopted over Dalton's own arcane notation. But Dalton's response to this problem seemed arbitrary (Rocke 1984, pp. 35-40). Finding a more natural solution became pressing during the first half of the nineteenth century: more and more elements were being discovered, and the elemental composition of more and more chemical substances was being determined qualitatively. Disagreement over how to assign atomic weights could only add to the confusion.

Just what chemical atomism was committed to is a subtle issue: Rocke (1984) makes clear that it should not be identified with either ancient atomism or early modern corpuscularianism, though many anti-atomists based their criticisms on just such an identification. However, the assumption that chemical atoms were relatively stable entities that could survive specified kinds of change studied by the discipline of chemistry directly mirrored, and offered a metaphysical explanation for, the assumption that chemical compounds are composed of material building blocks which can survive through specific kinds of chemical change. Needham (2004) has argued that Dalton's atoms are merely projections down from elemental substances to the atomic level, and therefore that Dalton 'gave us no explanation at all' of chemical phenomena (2004, p. 1039). I think that the premise of Needham's argument is exactly right, but I would reject the conclusion. However thin one might think Dalton's atomist explanation to be, it excludes other possible explanations, including any explanation that assumes the underlying continuity of matter.

\subsection{Mendeleev}

It is sometimes said that the growth in the number of the elements during the first half of the nineteenth century made a system of the elements necessary. The Karlsruhe Congress of 1860, after which Cannizzaro's method for determining the atomic weights of the elements was adopted by international consensus, made such a system possible. It is only with respect to this agreement that Mendeleev and others could embark on the project of investigating what connection there is, if any, between the atomic weights of the elements and their chemical properties. For an element's chemical properties include the stoichiometry of its compounds, and the determination of stoichiometry is possible only on the basis of atomic (or equivalent) weight assignments. With atomic weights in hand, the route by which Mendeleev reached the periodic table is clear. First came a preliminary list of the elements by atomic weight. Next came a careful noting of the trends and patterns in their chemical behaviour, including the stoichiometry and physical properties of their compounds. Through reflective equilibrium between data and hypothesis, Mendeleev was able to revise some atomic weights, and to recognise where gaps must be left for undiscovered elements. This is how the periodic table could provide the basis of novel predictions: new elements (Bensaude-Vincent 1986; Brush 1996). Mendeleev's table is a list of elements, but not of laboratory substances or Lavoisier's end points of analysis. The comparisons and analogies with respect to which Mendeleev drew up the periodic table concern the properties of elements taken across their different states of combination. Take chlorine: the substance that appears in the table below fluorine is not the green gas which is used up in the production of, say, $\mathrm{HCl}$ 
or $\mathrm{NaCl}$. Some of the properties conferring on chlorine its place in the table are physical properties of chlorine compounds, not of the gas. As a place-holder in the table of the elements, chlorine must be a substance capable of surviving changes in its state of chemical combination. In purely logical terms, this implies that the extension of 'chlorine' qua element includes both the green gas and the common component of $\mathrm{HCl}$ and $\mathrm{NaCl}$. The same abstraction applies to elements in their different phases, and the different allotropes of such elements as carbon and sulphur.

Although he was not the only chemist to do so (Bensaude-Vincent 1986, p. 11), Mendeleev stressed this important abstractness in the notion of element throughout his publications on the periodic law, and for good reason. Because chemistry is concerned with explaining chemical change, a system of the elements should contain substances that can survive change in phase, and in state of chemical combination:

$[\mathrm{N}] \mathrm{o}$ matter how the properties of a simple body may change in the free state, something remains constant, and when the elements form compounds, this something has a material value and establishes the characteristics of the compounds which include the given element. In this respect, we know only one constant peculiar to an element, namely, the atomic weight. The size of the atomic weight, by the very essence of the matter, is a number which is not related to the state of division of the simple body but to the material part which is common to the simple body and all its compounds. The atomic weight belongs not to coal or the diamond, but to carbon. (Mendeleev 1869, p. 439)

The placing of particular elements in the periodic table reflects the 'periodic law', which Mendeleev regarded as an empirical discovery that he had made in the 9 years between the Karlsruhe Congress and his first paper on the periodic system in 1869 . As he formulated it later:

The properties of simple bodies, the constitutions of their compounds, as well as the properties of these last, are periodic functions of the atomic weights of the elements. (Mendeleev 1879, p. 267)

The periodic law consists of a complex correlation between the atomic weights of the elements and their chemical and physical behaviour, and its very formulation depends on the distinction between simple bodies and elements proper. Of course the periodic law is no simple empirical claim, and its status must have been hypothetical, for it went far beyond the physical and chemical data about the elements, allowing Mendeleev to correct individual atomic weights and to identify places for as-yet undiscovered elements such as gallium and germanium. However, it was an empirical law nonetheless, and Mendeleev saw that this correlation demanded an explanation, but differed sharply from other chemists in the kind of explanation he saw as appropriate. Although he accepted Dalton's identification of the elements as classes of like atoms, he rejected the Proutian explanation according to which the chemical and physical properties of the elements are determined by the nature of their constitution from some sub-elemental primary matter. Rather, he regarded atoms as 'chemical individuals' (Mendeleev 1889, p. 640), whose essential property is their mass: 
[A]ll masses are nothing but aggregations, or additions, of chemical atoms which would best be described as chemical individuals.... The periodic law has shown that our chemical individuals display a harmonic periodicity of properties, dependent on their masses. (Mendeleev 1889, p. 640)

Like a Newtonian body interacting according to the law of gravitation, an atom's interactions with other massive bodies are determined by its mass, but Mendeleev sought no deeper explanation of why those masses take the values they do, or of their behaviour in terms of their internal structure. In fact he rejected the need for such an explanation, on both empirical and epistemological grounds. Later in his career this rejection came under some pressure from the emerging phenomenon of radioactivity. Others saw in radioactivity the possibility of transmutation between elements. Mendeleev saw in transmutation only the resurrection of alchemy and Proutian speculation, though he saw the need for an alternative explanation for the phenomenon of radioactivity. Given that radioactivity was, at the turn of the last century, associated with a few heavy atoms, he sought the explanation in their masses once again (Bensaude-Vincent 1982; Gordin 1998, 2004). In 1902 he published a paper awarding the luminiferous ether, the theoretical medium of transmission of Maxwell's electric waves, a place as a chemical element in the periodic table. Mendeleev likened the ether to a noble gas, an 'elastic fluid having no cohesion between its parts' (Mendeleev, quoted in Gordin 1998, p. 99). Although largely chemically inert, the ether was supposed to interact chemically with ponderable matter in the extreme gravitational circumstances of the environment of very heavy atoms like those of uranium or radium. Radioactivity could then be explained as the release of energy produced by this gravitational-yet still chemical-interaction between heavy atom and ether.

Mendeleev's chemical conception of the ether looks very much like an extension of the causal relationship he saw between mass and chemical behaviour, a causal relationship he saw as explaining the empirical periodic law. Both the causal explanation of the periodic law, and its extension to the explanation of radioactivity, turned out to be erroneous. The correlation between atomic weight and elemental behaviour encoded in the periodic law reflects their joint determination by a common cause: nuclear structure. Nuclear structure is a cause of chemical behaviour, via electronic shell structure. As measured by chemists (though unbeknown to them at the time), atomic weight is a property not of individual atoms, but of populations of atoms which are diverse in respect of atomic weight. It is a weighted average reflecting the distribution of atomic masses possessed by individual atoms. That distribution reflects the relative stability of the various isotopes (and therefore their structure) and the processes by which they were made. Mendeleev took the correlations to which this relation of common causation gave rise as evidence for a direct causal relationship.

\subsection{The twentieth century}

Mendeleev, like Dalton, regarded the atoms of a particular element as alike in respect of their weight, but that assumption was discarded when isotopy was discovered in the early twentieth century. It happened via the discovery of radioactivity by Henri Becquerel at the very end of the nineteenth century. It was not clear at first whether 
the underlying process was intrinsic to atoms: as we saw, Mendeleev thought that it arose from a chemical interaction between heavy atoms and the ether (see Gordin 2004, Chapter 8). If it were a process of atomic disintegration, however, it made sense to analyse the decay products, new species whose place in the periodic table was unclear. Some of the decay products were found to be inseparable by chemical means from known elements, from which they had different atomic weights and radioactive properties (see Soddy 1966, pp. 374-383). In 1910 Soddy proposed that the new elements should occupy the same place in the periodic table as the known elements they resembled, being not merely analogous, but chemically identical to them, and coined the term 'isotope' for the co-occupants. At first, isotopy seemed to be a relatively rare phenomenon, confined to a few species of heavy elements, but it was shown to be more common with the development of mass spectrography (see Bruzzaniti and Robotti 1989), and H. G. Moseley's method for measuring nuclear charge, the property which isotopes share.

Many familiar elements turned out to have a number of different isotopes. In such cases the atomic weight as measured by earlier chemists reflected not a property of individual atoms, but the average of a population of atoms that was heterogeneous in respect of atomic weight. It could not be atomic weight that determined the chemical properties of an element, because the atoms of an element may differ in their atomic weight, and atoms of different elements may be alike in theirs. Dalton and Mendeleev had turned out to be mistaken. There was some debate on how close were the chemical properties of different isotopes (see van der Vet 1979; Kragh 2000), but in 1923 the International Committee on Chemical Elements, appointed by the International Union of Pure and Applied Chemistry, enshrined the importance of nuclear charge as the determinant of the identity of the chemical elements (see Aston et al. 1923).

It is possible to overdramatize this change, seeing it as a fundamental shift in the concept of an element. I think this would be mistaken. There seems to be no reason to think that the idea that atoms of the same element should be alike in respect of their atomic weight was ever an integral part of the concept of element. The assumption was discarded while the overall explanatory role of elements in chemical change was preserved, so I would argue that it is more plausible to see it as an additional hypothesis (a false one) concerning the essential property whose persistence underwrites the truth of APE. Seeing things in this way allows us to recognize the continuity in the explanatory role of the elements, from Lavoisier through to the twentieth century, which I am trying to demonstrate in this paper. If that is correct then the view of the elements that emerged from the discoveries of radioactivity and of isotopy should be seen as the emergence of a new theoretical context for an old concept, rather than as the emergence of a new concept of element.

\section{Metaphysics, science and scientific realism}

Now that we have traced APE through the history of chemistry, we are in a position to discuss its epistemic status. Is it true, according to modern chemistry? If it is something that can be known now, when did it become known? When it became known, were the grounds a priori or a posteriori? Modern chemistry clearly vindicates APE: elements 
survive in their compounds because nuclear charge, the elemental property by which chemistry has individuated the elements since 1923, is preserved across chemical change (see Hendry 2006 for discussion). ${ }^{5}$ Since the facts that make APE true were discovered only in the twentieth century, it must count as an empirical discovery.

If APE is true, then in principle it could be known, but it is very hard to say that Lavoisier could have known APE to be true. It is difficult even to say that he believed it. His theories, his methods (including gravimetry) and his ways of describing chemical change may involve a presumption of its truth, but that does not imply that he would have asserted it if pressed. Nor could one say that he would have had any justification for asserting its truth, if it is made true by facts that only became known in the twentieth century. One might therefore say that APE was available to Lavoisier as a tacit working presumption about how a theory of composition should work, but that is not the same as saying that he knew it to be true. Such an assumption would be 'justified' only in the sense that it was permissible to make it while pursuing his compositional research programme. This is not the same as justification in the more traditional epistemological sense (a sufficient reason for belief). Seeking that kind of justification for a working assumption in a research programme, before that programme has got going, puts the cart before the horse. Whatever justification there could have been would emerge through the empirical success of the programme.

APE is clearly a natural way to understand chemical composition and change. It might even be a psychologically natural assumption to make, in the same way that it is natural for babies, after a certain stage in their cognitive development, to structure their world on the basis of object constancy. None of that implies that APE can be known a priori. If assuming APE is only a psychological tendency, then further reflection might allow one to resist it. I think that further reflection does show that APE can be resisted: Aristotle's account of chemical combination denies APE, and yet is perfectly coherent.

According to Aristotle, elements are only potentially present when combined in a mixt. ${ }^{6}$ Aristotle developed his view in opposition to atomism, according to which the ultimate components of things persist unchanged in more complex bodies, differences between things being explained by their different arrangements. Aristotle argued that if elements combine to form a new substance, as opposed to merely being juxtaposed, the product must be homogeneous. However, if atoms are assumed to be immutable then (he argued) atomism can accommodate only juxtaposition, and so cannot recognise the distinction between mere juxtaposition and genuine combination (Needham 2009). Aristotle's positive counterproposal is to generate the elements from opposed pairs of properties: hot and cold, wet and dry. The elements correspond to maximal degrees of compatible pairs of these properties: air is what is hot and wet, water is what is cold and

\footnotetext{
${ }^{5}$ Even though it is an atomic property that vindicates APE, modern chemistry does not vindicate every aspect of chemical atomism. It contradicts other key atomist assumptions about composition and change that are shared by Dalton and Mendeleev (see Needham and Hendry 2018).

6 Following Needham (2006, 2009), from whom this brief sketch is derived, I use the archaic term 'mixt' to indicate that Aristotle does not distinguish between compounds and homogeneous mixtures such as solutions. Chalmers (2011) articulates a different interpretation of Aristotle, but which particular interpretation of Aristotle is correct is not material to my argument here: all I need is that the 'Aristotelian' account set out by Needham is intelligible.
} 
wet, fire is what is hot and dry, and earth is what is cold and dry. In combination, the essential properties of the elements are blended, so that a mixt will have sub-maximal degrees of heat or cold, wetness or dryness. Since a mixt is homogeneous, the elements are not actually present in the mixt because no part of the mixt possesses the essential properties of any of the elements. What does persist? Needham interprets Aristotle's view as taking the continuants of change to be portions of matter that bear substance properties, including a potential to display the elemental properties once again (2009). Only in this sense_-potentiality — can the elements be said to be 'in' the mixt.

If APE is a constitutive principle, which can be known a priori, of what is it constitutive? The concept of element? The intelligibility (to us) of Aristotle's account of composition is (defeasible) evidence that that account is coherent. If Aristotle's account is coherent, then it does not violate any rational constraint on the application of the concept of element. In which case APE can be coherently denied, and is not constitutive of our concept of an element. Now one might instead see the applicability of the concept of element as depending on continuity across chemical change: chemical reactions involve change, but sequential change requires continuity, that a series of chemical changes has a persisting subject to which it happens. That too would be insufficient justification for APE. According to Needham, Aristotle has matter as the continuant: chemical changes are things that happen to portions of matter. Therefore even if continuity across chemical change is a requirement for the proper applicability of the concept of a chemical element, it can be met without assuming that elements survive in their compounds. ${ }^{7}$

One might challenge this argument by pointing out that conceptions of the elements have changed quite radically across the history of science. Even if Aristotle's account is intelligible to a modern philosopher or scientist, perhaps it was not for Lavoisier. I am aware of no positive textual justification for this claim in Lavoisier's own work. Consider, by analogy, Lavoisier's assumption that the property of acidity is conferred by the presence of oxygen. Should we say that this assumption is false, or that it is part of Lavoisier's conception of acidity? If we can regard Lavoisier as being able to reason about acids, then we can regard him as being mistaken about the nature of acids (I think we can). Then we can say that Lavoisier's assumption about acidity turned out to be false, as did every subsequent theory according to which the property of acidity is conferred by the presence of a particular element (see Hendry 2005, 2010). Now Lavoisier reasons about elements and their role in chemical change in ways that are perfectly familiar to modern science. APE was a constraint on his reasoning, but it might have turned out to be false, so it is more plausible to regard it as a factual assumption, even in Lavoisier's system. This is not a knockdown argument, for it relies on a prior stance: that historical philosophers and scientists can (sometimes) reason about the same world we find ourselves in, and are capable of being mistaken about

\footnotetext{
7 Chang (2009) has introduced the idea of 'ontological principles', the applicability of which are preconditions for scientific understanding. For Chang, ' $[\mathrm{t}]$ he hallmark of an ontological principle is that its denial should strike us as nonsensical, rather than false' (2009, p. 68). The Aristotelian account of combination strikes the modern reader as merely false, but it violates APE. I conclude that APE is not an ontological principle of the kind identified by Chang. The Aristotelian account does satisfy what Chang calls 'the principle of subsistence', which is a precondition for the 'activity of narration' (2009, p. 73), which involves following a continuant through a series of changes. As noted above, matter is the continuant for Aristotle.
} 
it. That stance could be challenged by specific textual evidence: that Lavoisier saw oxygen as conceptually (as opposed to materially) constitutive of acidity, or that he saw APE as conceptually constitutive of being an element. Such evidence is (so far as I am aware) entirely lacking.

Rather than an a priori regulative principle, I would argue that APE should be viewed as a metaphysical principle, but one that was nonetheless able to play an important regulative and heuristic role in the development of theories of chemical composition and structure from the eighteenth century onwards. By 'metaphysical' I mean 'of, or pertaining to, existence or reality.' A metaphysical principle is a general or abstract claim about how things are, rather than a convention or a necessary precondition for knowledge in any particular domain. Being 'metaphysical' in this sense does not imply untestability or unverifiability. Metaphysical principles may be hard to test or verify, and may even be impossible to test or verify on their own, but the same is true of many scientific theories. Being metaphysical does not exclude being an integral part of science. Indeed metaphysical principles have often been articulated explicitly by scientists (consider, for instance, Newton's commitment to absolute time and space), but often they are unarticulated, even though they regulate a scientist's inferences about the categories they govern. The virtue of understanding APE as a metaphysical principle is precisely that one can trace it continuously through the history of chemistry, from a time when it was unarticulated (in Lavoisier's work), to a time when it was acknowledged explicitly (in Mendeleev's work).

From the 1950s onwards, philosophers based at the London School of Economics developed contrasting accounts of how this might work. One might say that the project of identifying a role for metaphysics in science was itself a research programme within broadly realist philosophy of science, supported by (and itself supporting) the broad view that the units of appraisal in science should be research programmes (that is, series of theories rather than the individual theories developed within such programmes). Hence in the remainder of this section I will critically examine, in roughly chronological order, proposals from Karl Popper, J. W. N. Watkins, Imre Lakatos and Elie Zahar.

To be worth the name, a realist account of the role of metaphysics in science should be committed to the following general principles. Firstly, metaphysical theories or principles are to be considered as factual claims: they (or at least, some abstract part of them) are to be interpreted realistically, so as to be semantically on a par with other theoretical claims in science, and their purported role in science should depend on that interpretation. Secondly, the role of metaphysical theories or principles should not be a merely psychological one of bringing a particular testable theory into the mind of a particular scientist. Seeing an apple fall at his home in Woolsthorpe is alleged to have played some role in bringing forth Newton's law of gravitation. ${ }^{8}$ While dozing off in front of a fire, August Kekule is alleged to have had a vision of a snake which seized its own tale, forming itself into a ring shape which, he said later, suggested to him his famous hexagonal formula for benzene (see Rocke 2010, Chapter 7). Under a realist conception, the role of metaphysical theories should not be

\footnotetext{
8 Whatever its truth, Richard Westfall observes that the apple story 'vulgarizes universal gravitation by treating it as a bright idea. A bright idea cannot shape a scientific tradition.' (1980, p. 155).
} 
merely suggestive, as the apple and the snake were to Newton and Kekulé. To support a realist inference the heuristic and regulative role should depend on the content of the metaphysical principle, literally construed. Thirdly, if such theories or principles are semantically on a par with testable scientific claims, and they can have a role in the development of theories which is more than merely suggestive, then it should be possible in principle to appraise the role of particular metaphysical theories or principles in particular scientific developments, in much the same way that abstract but still scientific principles in physics are given credit for the empirical success in the theoretical developments in which they play an important role.

This assumes a view of the role of metaphysics in science that is congenial to scientific realism, but it requires more than that. Not every scientific realist may wish to give a realist account of the role of metaphysics in science. One may be a realist about science, but think that metaphysics has only a harmful effect on it. Or one may admit that metaphysical principles may (sometimes) play a role, but never in a way that could ground an argument in favour of their truth. I think that metaphysical principles can play a role in empirical science that does allow them to accrue positive support. It remains to describe how that is even possible.

In a short though well-known passage in the postscript to the Logic of Scientific Discovery, Popper tried to articulate a role for metaphysics in science, but the title of the section makes clear that the role is limited, failing to meet two of our three criteria for a realist conception of the role of metaphysics in science: 'Why Even Pseudo-Sciences May Well Be Meaningful. Metaphysical Programmes for Science.' (1983, pp. 189-93) His discussion begins by restating his falsificationist criterion of demarcation, which 'singles out those theories which can be seriously discussed in terms of experience' (1983, p. 189). But the scientist takes a risk in neglecting to study pseudo-scientific and metaphysical theories that fail to meet this criterion, from which 'something of real interest' may be learned. He argued that disdain for astrology, for instance, could blind the scientist to astronomical possibilities, such as the influence of the moon on the tides, and acknowledged that Kepler 'belonged to the astrological tradition', although he 'never tired of submitting his hypotheses to ingenious and highly critical tests' (1983, p. 190). Popper's central example of a 'highly important metaphysical theory' (1983, p. 191), is atomism:

The metaphysical character of the 'corpuscular theory', before Avogadro at any rate, is clear. There was no possibility of refuting it. Failure to detect the corpuscles, or any evidence for them, could always be explained by pointing out that they were too small to be detected. Only with a theory that led to an estimate of the size of the molecules was this line of escape more or less blocked, so that refutation became in principle possible. (Popper 1983, p. 191)

According to Popper, atomism is a metaphysical theory not only because it was untestable, but also because it 'conceived the world in terms of a vast generalization, on the grandest scale' (1983, p. 191), and 'explained the known in terms of the unknown: it constructed an unknown and invisible world behind our known world' (1983, p. 192). For Popper, its value to science was that it could be supplemented with further assumptions so as to become testable (1983, p. 191). Hence it would be 'grossly misleading to describe it as meaningless; and very risky to reject it out of hand, as did 
Mach.' (1983, p. 191) Of course by becoming testable, atomism became a scientific theory, but even an untestable theory can 'indicate the direction of our search, and the kind of explanation that might satisfy us'. (1983, p. 193) Thus the unfalsifiable existential claim 'there exists a philosopher's stone' (1983, p. 193) 'proved suggestive and even fruitful in the history of science' (presumably through its influence on alchemy), despite the fact that it was 'never verified and is now believed by nobody' (1983, p. 193).

Three things are worth noting from Popper's discussion. Firstly, he never distinguishes metaphysics from pseudo-science. Both are irrefutable, and the terms in which he characterises metaphysics (great generality, explaining the known in terms of the unknown, or the invisible) are somewhat vague and hardly distinctive of metaphysics. These features are shared also by many scientific theories, as Popper admits. Secondly, there are two ways for a non-scientific theory to be of value to science. Atomism became testable when it was augmented so as to become testable. By doing so it ceased to be metaphysical, but other theories have remained untestable and yet were suggestive of empirical work. Popper does not indicate whether they did so by suggesting testable hypotheses, but even if they did, this role would allow them to be relegated to the (psychological) context of discovery. Of Kepler's attitude to astrology he notes 'here, as so often ... important hypotheses may originate from truly fantastic ideas: the origin never matters, as long as the hypothesis is testable.' (1983, p. 191) Thirdly, if metaphysical theories can become scientific theories when they are augmented with further assumptions, then it seems that a theory's status as metaphysical is not intrinsic to it. This seems especially true if, as in the case of atomism, the additional claims are relatively low level, such as an estimate of molecular size. Now Popper in fact misidentifies how atomism became a part of science: testable estimates of the physical properties of atoms became available only in the twentieth century, through a process of triangulation conceived by Jean Perrin (see Nye 1972). This was many years after atomism became a part of science: broadly atomist theories of molecular structure had been testable at least indirectly by chemical means since the $1860 \mathrm{~s}$, through a process that Alan Rocke has called 'isomer counting' (see Rocke 2010, Chapter 7). Like so many twentieth-century philosophers of science, Popper tended to ignore chemistry.

On the basic logical point that what is metaphysical (because untestable) can become scientific (because testable) merely by being conjoined with other statements, Popper is clearly right. Moreover, in the twentieth century the point needed to be made. But the consequence of recognising this important truth is that the distinction between scientific and metaphysical theories immediately becomes contextual and therefore historically contingent, rather than a timeless feature of their content or logical form, because it depends on whether a particular theory happens to have been proposed alongside other statements together with which it implies some empirically testable consequence. In fact the distinction between metaphysics and science seems to dissolve entirely. ${ }^{9}$ Other theories that Popper regarded as unambiguously scientific, such as Newtonian mechanics, were also untestable in isolation, requiring augmentation

\footnotetext{
9 For that reason, if the category 'metaphysics' is to have any role in analysing science and its development, it must be identified independently from its supposed distinctness from science, as I do above.
} 
by auxiliary assumptions, and he explicitly characterised Darwin's theory of evolution, which for most other philosophers is part of science, as a 'metaphysical research programme' (1974, pp. 133-143).

Popper rightly rejected meaning as the aspect under which science should be distinguished from non-science. Moreover, the idea that a metaphysical theory can become testable (and therefore scientific) by augmentation supports our first condition: the semantic parity of metaphysics and science. It is hard to see how adding further premises can magically transform metaphysics into science, if the two things are essentially different in the nature of their content or their logical form. However, for Popper, a metaphysical theory that remains untestable cannot be part of science. Even though one may call it 'important' it is hard to see how its suggestive role is any different from that of Newton's apple or Kekulé's snake, since, as we saw, he also held that the origin of a testable theory 'never matters'. This odd and somewhat conflicted stance on the role of metaphysics in science is forced on Popper by his retention of the falsificationist demarcation criterion. Metaphysical principles cannot be fully be a part of science because they are untestable.

Watkins used a tinker-toy example-'haunted-universe doctrines' (1958, p. 344) - to give an account of the role of metaphysics in science that is still broadly Popperian, but more nuanced than Popper's own view. Consider a castle that is reputed to be haunted. Because it involves an existential claim ('something is there' (p. 344)), this belief is irrefutable, though it may also be 'dramatically though inconclusively confirmed by eerie experiences' (p. 344). Some metaphysical theories are, or entail, claims of a closely related form, argues Watkins: those that 'allege the veiled existence of something in the universe of which we may seem to catch confirming glimpses' (p. 344). Since they are inconclusively confirmable yet irrefutable, they 'enjoy a special privilege in the struggle of ideas for existence' (p. 344). They are 'extra-scientific' yet can influence the development of scientific theories.

The logical form of a typical 'haunted-universe doctrine' involves both universal and existential quantification (1958, p. 346), a relatively low-level example from chemistry being 'for any metal there is an acid which will dissolve it' (1958, p. 346). Determinism is often understood as the claim that 'every event has a cause' (1958, p. 348). On the assumption that a causal claim such as ' $X$ causes $Y$ ' requires that there is a law of nature which subsumes the relationship between the two, determinism prescribes that scientists search for natural laws (1958, p. 356). Likewise mechanism, understood as the claim that '[f]or every physical change there exist contiguous and contemporaneous factors causing that change' (1958, p. 350), prescribes that scientists never accept 'occult qualities, action at a distance, instantaneous transmission or any other departures from the principle of action by contact' (1958, p. 356).

Now it might be the case that every metaphysical doctrine can be expressed in this form, or entails a claim that can be put into this form. The claim that all metaphysical claims in science can be construed as having this form (i.e. haunted-universe doctrines) might well be trivial if no restriction were to be made as to which classes of entities might be introduced for the quantifiers to range over. Interestingly, this stronger claim is itself of the same logical form as haunted-universe doctrines, though with secondorder quantifiers: for every metaphysical theory there exists a class of entities which, when quantified over, allow an equivalent statement to be formulated in 'haunted- 
universe' form. However, Watkins quite sensibly never proposes that all metaphysical claims can be expressed in this way, making only the weaker claim that 'this structure is common to a number of extra-scientific ideas which have seriously influenced the development of science' (1958, p. 344).

The core of the compositional programme in chemistry can be reformulated in line with Watkins' proposal: for every compound substance there are elemental substances of which it is (materially) composed. This claim, however, is a consequence of a logically stronger claim, one that chemists after Lavoisier would also have endorsed: there are elemental substances of which every chemical substance is (materially) composed. In isolation these claims are irrefutable, but confirmable, and the work of chemists from the 1790s onwards, filling out Lavoisier's table of simple substances, confirmed them by instantiation. Along the way a few of the simple substances conceived by Lavoisier were deleted (caloric, light), and individual compositional claims revised (it came to be accepted that the acid of sea salt contained no oxygen). Moreover, as Zahar points out (2007, p. 139) the metaphysical character of Watkins' haunted-universe doctrines derives not from the concepts they contain, or the unobservable nature of the entities they quantify over, but from their logical form: 'for every substance there is some substance in which it dissolves' involves the observable relation ' $x$ dissolves $y$ ', and yet is as clearly metaphysical (because unfalsifiable) as 'every event has a cause.' The idea of a haunted-universe doctrine seems genuinely to illuminate the compositional programme in chemistry, and the metaphysical character of its central claims: an existential claim motivates a search for its truth-maker, which might be a ghost, a solvent or multiple chemical elements.

However, Watkins' acceptance of the falsificationist criterion of demarcation between science and non-science means that his view faces the same fatal difficulty as Popper's. Metaphysics remains something other than science: 'between the realm of analytic truths and the realm of empirical statements there is a no-mans'-land of haunted-universe doctrines' (1958, p. 359). This rigid separation entails that even where a haunted-universe doctrine plays an important role in science, this can provide no simple argument in favour of its truth because (i) different parts of science might support different metaphysical theories; (ii) empirical theories supporting metaphysical theories would allow them to discourage competition (1958, pp. 363-365). One cannot help but think that if metaphysical theories are simply taken to be a part of science, these difficulties disappear, or at least present no more difficulties than logical clashes between successful scientific theories.

Popper regarded Lakatos' Methodology of Scientific Research Programmes as a development of his idea of a metaphysical research programme. ${ }^{10}$ This is unfair in a number of ways, but for our present discussion there is one really important difference between the two. In a review of Lakatos' collected papers Ian Hacking noted that Lakatos effected a 'shift from Popper's demarcation problem' (1979, p. 384):

Popper arrived at an implicit division into science, metaphysics and muck. Metaphysics is the earnest speculation that can some day lead to positive science. The

10 See Popper (1974, p. 175) (note 242). 
logical positivists had science versus metaphysics-muck, but Popper had a better set of distinctions in mind, illustrated by the fact that the muck has now organised itself as something apart from speculative metaphysics. Lakatos now is willing to lump the metaphysics that becomes science alongside science itself, because it is part of the larger growth of knowledge that concerns him. Thus metaphysics-science confronts the muck. (Hacking 1979, pp. 384-385)

It is worth making two comments here. Firstly, the idea that 'metaphysics-science confronts the muck' no more invokes fixed metaphysics than it does fixed science. Lakatos was a thoroughgoing fallibilist. Change is possible in any part of science, metaphysics included. A research programme with an associated metaphysics may be replaced at any time by a more successful research programme with a quite different metaphysics. Science qua science has no metaphysical foundations. Secondly, even the phrase 'metaphysics-science confronts the muck' suggests too much of a contrast between science and metaphysics. Commenting on the Popperians Joseph Agassi and John Watkins, Lakatos observes

I go much further than they in blurring the demarcation between [Popper's] 'science' and [Popper's] 'metaphysics': I do not even use the term 'metaphysical' any more. I only talk about scientific research programmes whose hard core is irrefutable not necessarily because of syntactical but possibly because of methodological reasons which have nothing to do with logical form. (1970, p. 184$)^{11}$

For Lakatos and Zahar, metaphysical assumptions are to be found at the very heart of science, in the hard core of a research programme (Zahar 1989, p. 21; 2007, p. 138). To that extent they are above the empirical fray, yet able to exert a heuristic and regulative role on the development of particular scientific theories through their 'prescriptive import' on the structure of physical laws and explanations (1989, p. 21). Thus according to Zahar, 'Special relativity is based on the metaphysical proposition that no privileged inertial frame exists. This leads to the prescription that all theories should assume the same form in all inertial frames' (1989, p. 21). Since a research programme is guided by its hard core, and research programmes can be evaluated empirically, the empirical success of a research programme really should reflect on its hard core. This answers one important question that, according to Zahar, 'Popper did not properly ask, let alone satisfactorily tackle' (2007, p. 141): 'does an experiment which corroborates a theory belonging to a program also support the metaphysics underpinning the program?' By answering this question in the positive, Zahar's account meets all three conditions for a realist conception of the role of metaphysics in science.

Acknowledgements Presentations based on this paper were presented at the workshop on 'First Principles in Science: Their Epistemic Status and Justification' at the Munich Centre for Mathematical Philosophy in June 2016, and at the workshop on Integrated History and Philosophy of Science at UCL in June 2018. I am most grateful to Catherine Herfeld and Milena Ivanova for the invitation to Munich, and to the audiences in Munich and UCL for their comments. I would also like to thank Alan Chalmers and an anonymous referee for detailed comments and suggestions on the written paper, which greatly improved it.

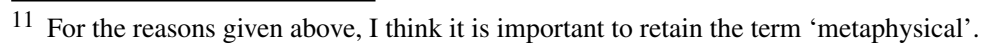


Open Access This article is distributed under the terms of the Creative Commons Attribution 4.0 International License (http://creativecommons.org/licenses/by/4.0/), which permits unrestricted use, distribution, and reproduction in any medium, provided you give appropriate credit to the original author(s) and the source, provide a link to the Creative Commons license, and indicate if changes were made.

\section{References}

Aston, F. W., et al. (1923). Report of the international committee on chemical elements. Journal of the American Chemical Society, 45, 866-874.

Bensaude-Vincent, B. (1982). L'éther, élément chimique: un essai malheureux de Mendeleev? British Journal for the History of Science, 15, 183-188.

Bensaude-Vincent, B. (1986). Mendeleev's periodic system of the elements. British Journal for the History of Science, 19, 3-17.

Blumenthal, G., \& Ladyman, J. (2017). The development of problems within the phlogiston theories, 1766-1791. Foundations of Chemistry, 19, 241-280.

Blumenthal, G., \& Ladyman, J. (2018). Theory comparison and choice in chemistry, 1766-1791. Foundations of Chemistry, 20, 169-189.

Boyle, R. (1661). The sceptical chymist. London.

Brush, S. (1996). The reception of Mendeleev's periodic law in America and Britain. Isis, 87, 595-628.

Bruzzaniti, G., \& Robotti, N. (1989). The affirmation of the concept of isotopy and the birth of mass spectrography. Archives Internationales d'Histoires des Sciences, 39, 309-334.

Cassebaum, H., \& Kauffman, G. (1976). The analytical concept of a chemical element in the work of Bergman and Scheele. Annals of Science, 33, 447-456.

Chalmers, A. (2009). The scientist's atom and the philosopher's stone: How science succeeded and philosophy failed to gain knowledge of atoms. Dordrecht: Springer.

Chalmers, A. (2011). Aristotle on homoeomerous substances. In: M. Rossetto, M. Tsianikas, G. Couvalis, M. Palaktsoglou (Eds.), Greek research in Australia: Proceedings of the eighth biennial international conference of Greek studies (pp. 19-26). Adelaide: Flinders University Department of Modern Languages.

Chang, H. (2009). Ontological principles and the intelligibility of epistemic activities. In H. De Regt, S. Leonelli, \& K. Eigner (Eds.), Scientific understanding: Philosophical perspectives (pp. 64-82). Pittsburgh: University of Pittsburgh Press.

Chang, H. (2012). Is water $\mathrm{H}_{2} \mathrm{O}$ ? Evidence, realism and pluralism. Berlin: Springer.

Geoffroy, E.-F. (1718). Table of the different relations observed in chemistry between different substances-27 August 1718. Translated in Science in Context, 9 (1996), 313-320.

Gordin, M. (1998). Making Newtons: Mendeleev, metrology, and the chemical ether. Ambix, 45, 96-115.

Gordin, M. (2004). A well-ordered thing: Dmitrii Mendeleev and the shadow of the periodic table. New York: Basic Books.

Hacking, I. (1979). Imre Lakatos's philosophy of science. British Journal for the Philosophy of Science, $30,381-410$.

Hendry, R. F. (2005). Lavoisier and Mendeleev on the elements. Foundations of Chemistry, 7, 31-48.

Hendry, R. F. (2006). Elements, compounds and other chemical kinds. Philosophy of Science, 73, 864-875.

Hendry, R. F. (2010). The elements and conceptual change. In H. Beebee \& N. Sabbarton-Leary (Eds.), The semantics and metaphysics of natural kinds. New York: Routledge.

Klein, U. (1994). Origin of the concept of chemical compound. Science in Context, 7, 163-204.

Klein, U., \& Lefèvre, W. (2007). Materials in eighteenth-century science: A historical ontology. Cambridge, MA: MIT Press.

Kragh, H. (2000). Conceptual changes in chemistry: The notion of a chemical element, ca. 1900-1925. Studies in History and Philosophy of Modern Physics, 31B, 435-450.

Lakatos, I. (1970). Falsification and the methodology of scientific research programmes. In I. Lakatos \& A. Musgrave (Eds.), Criticism and the growth of knowledge (pp. 91-196). Cambridge: Cambridge University Press.

Lavoisier, A. (1790). The elements of chemistry. Edinburgh: William Creech. Translation by Robert Kerr of Traité Élémentaire de Chimie (Paris, 1789). 
Leicester, H. M., \& Klickstein, H. S. (Eds.). (1952). A source book in chemistry 1400-1900. Cambridge, MA: Harvard University Press.

Macquer, P. (1768). Elements of the theory and practice of chemistry. London: Alexander Donaldson.

Mendeleev, D. I. (1869). The relation between the properties and atomic weights of the elements. Journal of the Russian Chemical Society, 1,60-77. Page references are to the translation in Leicester and Klickstein 1952, pp. 439-442.

Mendeleev, D. I. (1879). The periodic law of the chemical elements. The Chemical News, XL: 267-268; reprinted in D. M. Knight (Ed.), Classical scientific papers-chemistry, 2nd Series. London: Mills and Boon, 1970.

Mendeleev, D. I. (1889). The periodic law of the Chemical elements. Journal of the Chemical Society, 55, 634-656; reprinted in D.M. Knight (Ed.), Classical scientific papers -Chemistry, 2nd Series. London: Mills and Boon, 1970.

Needham, P. (2004). Has Daltonian atomism provided chemistry with any explanations? Philosophy of Science, 71, 1038-1047.

Needham, P. (2006). Aristotle's theory of chemical reaction and chemical substances. In D. Baird, L. McIntyre, \& E. Scerri (Eds.), Philosophy of chemistry: Synthesis of a new discipline (pp. 43-67). Dordrecht: Springer.

Needham, P. (2009). An Aristotelian theory of chemical substance. Logical Analysis and History of Philosophy, 12, 149-164.

Needham, P., \& Hendry, R. F. (2018). Aspects of the concept of potentiality in chemistry. In K. Engelhard \& M. Quante (Eds.), Handbook of potentiality (pp. 375-400). Berlin: Springer.

Nye, M. J. (1972). Molecular reality: A perspective on the scientific work of Jean Perrin. London: Macdonald \& Co.

Popper, K. (1974). Intellectual biography. In P. A. Schilpp (Ed.), The philosophy of Karl Popper (pp. 3-181). La Salle, IL: Open Court.

Popper, K. (1983). Realism and the aim of science. London: Hutchinson.

Rocke, A. (1984). Chemical atomism in the nineteenth century: From Dalton to Cannizzaro. Columbus, $\mathrm{OH}$ : Ohio State University Press.

Rocke, A. (2010). Image and reality: Kekulé, Kopp and the scientific imagination. Chicago: University of Chicago Press.

Siegfried, R. (2002). From elements to atoms: A history of chemical composition. Philadelphia: American Philosophical Society.

Soddy, F. (1966). The origins of the conceptions of isotopes. In Nobel lectures, chemistry 1901-1921 (pp. 371-399). Amsterdam: Elsevier.

van der Vet, P. (1979). The debate between F.A. Paneth, G. von Hevesy and K. Fajans on the concept of chemical identity. Janus, 92, 285-303.

Watkins, J. W. N. (1958). Confirmable and influential metaphysics. Mind, 67, 344-365.

Westfall, R. S. (1980). Never at rest: A biography of Isaac Newton. Cambridge: Cambridge University Press.

Zahar, E. (1989). Einstein's revolution: A study in heuristic. La Salle, IL: Open Court.

Zahar, E. (2007). Why science needs metaphysics: A plea for structural realism. La Salle, IL: Open Court.

Publisher's Note Springer Nature remains neutral with regard to jurisdictional claims in published maps and institutional affiliations 